\title{
Neuromarketing: The popularity of the brain-imaging and physiological tools
}

\author{
Ahmed H. Alsharif *, Nor Zafir Md Salleh and Rohaizat Baharun \\ * Correspondence: ahmedalsharif07@gmail.com; Tel.: +60-1161271610 \\ Received: 27 June 2021; Accepted: 20 August 2021; Published: 4 September 2021 \\ Edited by: Aida Azlina Mansor (Universiti Teknologi MARA, Malaysia) \\ Reviewed by: Tahamina Begum (Universiti Sains Malaysia, Malaysia); \\ Muhamad Kamal Mohammed Amin (Universiti Teknologi Malaysia, Malaysia) \\ https://doi.org/10.31117/neuroscirn.v3i5.80
}

Azman Hashim International Business School, Universiti Teknologi Malaysia, 81310 Skudai, Johor, Malaysia.

\begin{abstract}
In the last two decades, neuromarketing (NM) studies are snowballed because scientists and researchers are looking for understanding the mechanisms of decision-making in the consumer's brain toward marketing stimuli, for example, but not limited to advertising and brands that have not changed overnight. For this purpose, NM research is using state-of-the-art technology to gauge the responses of consumers' minds to marketing stimuli, which is impossible by traditional marketing methods. In this paper, we have concentrated on neuromarketing tools such as functional magnetic resonance imaging (fMRI), electroencephalography (EEG), and eye-tracking (ET). Literature indicates that EEG, $\mathrm{FMRI}$, and ET enable to gauge consumers' neurometrics and biometrics responses; thereby, they provide valuable information about the physiological and mental reactions toward marketing stimuli, which can be used to improve marketing research. Neuromarketing can provide valuable information about consumer behaviour, which is impossible by traditional methods. We hope that this study provides valuable insights into neuromarketing and future directions.
\end{abstract}

Keywords: neuromarketing; marketing; neuromarketing tools; consumer behaviour;

C2021 by the Alsharif et al. for use and distribution according to the Creative Commons Attribution (CC BY-NC 4.0) license (https://creativecommons.org/licenses/by-nc/4.0/), which permits unrestricted non-commercial use, distribution, and reproduction in any medium, provided the original author and source are credited.

\subsection{INTRODUCTION}

Neuromarketing (NM) is an interdisciplinary field that has derived from neuroscience, psychology, and marketing (Mansor \& Isa, 2020). Undoubtedly, this is a promising field to study how humans made their conscious/unconscious decisions, and so through recording the activity regions in the consumer's brain when the consumer has been exposed to marketing stimuli such as advertisements, brand, sound, and so forth (Cruz et al., 2016). Traditional marketing methods are often providing not reliable and inaccurate information because it depends on the verbal consumer's choice (self-report) (Alsharif et al., 2021c). Therefore, traditional methods such as surveys, focus groups, and interviews are not suitable for measuring unconscious responses (Colaferro \& Crescitelli, 2014).

NM and traditional marketing methods are complementary; the reason turns back to that NM does not use similar techniques as in conventional methods (Ramsoy, 2015). NM uses state-of-the-art technology such as fMRI, EEG, and ET to study, explore, and analyse consumers' neural and physiological responses toward marketing stimuli to enhance the marketing strategies and the accuracy of the predictions. Hence, the marketers and practitioners have enormously sought to explore what is in the consumers' brains and what they are thinking of and explore the concealed centres in the 
brain (Alsharif et al., 2020b), which lead the consumers to make their decisions, satisfy their needs and desires. Marketing has moved from studying conscious behaviour to study unconscious behaviour by state-ofthe-art technology such as fMRI, EEG, and ET (Fortunato et al., 2014; Stanton et al., 2017).

According to Stanton et al. (2017), NM has several methods to measure the consumer responses toward marketing stimuli, which have divided into three main categories: i) brain imaging tools such as $\mathrm{fMRI}$ and EEG, ii) Physiological tools such as ET, galvanic skin response (GSR), iii) Interventions tools such as transcranial magnetic stimulation (TMS) and neurotransmitters. Undoubtedly, all these methods are using in neuromarketing. However, the fMRI and EEG are still the most popular brain imaging tools among scholars because $\mathrm{AMRI}$ and EEG are the most promising tools to perform NM research. These tools are studying, exploring, and analysing the neural responses of consumers toward marketing stimuli such as ads, products, brands, and prices. Meanwhile, ET is considered the popular physiological tool to record eye movements, attention, fixations, saccade, pupil dilation (Alsharif et al., 2021b; Alsharif et al., 2021d). In this study, the authors concentrate on the fMRI, EEG, and ET because these methods give a more accurate picture of the activity regions in mind timely, cost, temporal resolution, spatial resolution compared with the other methods. Therefore, the key contributions of the current study are summarised, as follows:

- Presents an overview of the NM field and the advantages of this field in marketing research.

- Provides the overview of the fMRI, EEG, and ET techniques used in marketing research.

- Provides new references to other researchers who need insights into enabling the $\mathrm{FMRI}, \mathrm{EEG}$, and $\mathrm{ET}$ methods in NM.

The organisation of this article is as thus; section 2 presents the advantages of neuromarketing tools in marketing research. Section 3 presents an overview of the $\mathrm{fMRI}, \mathrm{EEG}$, and ET techniques used in marketing research. Finally, Section 4 concludes the work and future directions of this field.

\subsection{THE ADVANTAGES OF NEUROMARKETING TOOLS IN MARKETING RESEARCH}

NM tools are primarily employed in advertising practices and marketing research. Therefore, NM is used to know how marketing stimuli, for example, but not limited to advertisements impact buying decisions
(Smidts et al., 2014; Venkatraman et al., 2015). For example, identifying the negative elements in advertising cause an individual's aversion to the products and allows to determine visual and audio features and select an appropriate media (Fugate, 2007). In addition, NM can also identify the real unfulfillment of consumers' needs; in such a way, it helps develop more useful and pleasant products, advertisements, and satiable the actual consumers' needs and desires (Eser et al., 2011). According to Fortunato et al. (2014), neuromarketing's contributions often helps in developing branding strategies and positioning a brand in the market. Furthermore, neuromarketing also can adjust its pricing strategy and developing brands and products. Therefore, NM techniques enable to determine the impact of emotion on purchase decisions mechanisms (Alsharif et al., 2021a; Fugate, 2007). In addition, it also can create more successful social initiatives, such as encouraging the usage of seat belts in cars (Orzan et al., 2012) and antismoking campaigns (Cartocci et al., 2018; Rossi et al., 2017). NM techniques can gauge the emotional arousal (e.g., high or low) to an advertising campaign, brands, product, services, besides, select the appropriate stimuli that affect the consumer effectively at the purchase point in-store (Cherubino et al., 2017; Kühn et al., 2016). Lifestyle nowadays is different from the past and, definitely, it will be different in the future; thereby, the markets relied on the period of time of the consumers' lifestyle to promote their products and brand by using creative ads which are corresponding with consumers lifestyle (Alsharif et al., 2021b).

Advances in brain-imaging and physiological technology have led to an increase in the number of publications about studying the human brain; thereby, getting accurate images of the human brain, which led to a better understanding of its structure and functions. Accordingly, researchers and scientists from other fields have been interested in applying neuroimaging tools in their research. For example, it has grabbed attention from huge business establishments to use these tools in their research to dive deep into the consumer's brain to know the underlying reasons for consumers' choices to satisfy their actual needs. Notably, by using neuroimaging and physiological tools, companies can only better understand the consumer's behaviour as the mechanisms of making-decision and what processes affect making-decision in the brain (Alsharif et al., 2021d). Lindstrom (2009) endorsed the benefits of the NM techniques for both consumers and firms when they discussed that products and advertising campaigns designed on neuromarketing techniques will benefit the 
consumer by guiding the consumer to make purchase decisions easier simple. Meanwhile, for firms, techniques will make advertisements and products more effective; thereby, reduce the wastage of firms budget used randomly on advertising campaigns.

\subsection{OVERVIEW OF NEUROMARKETING TOOLS}

According to the literature, we found techniques to measure brain activity signals such as $\mathrm{FMRI}$ and EEG, physiological activity signals such as ET and GSR, and intervention tools like TMS. As well we found studies about other tools such as MEG, PET, and SST are scant. However, it is worthy to mentions that several studies have employed other tools such as observations, interviews, focus groups, questionnaires, and reaction time to measure/record consumers' behaviour. NM techniques are essential for marketing research (Alsharif et al., 2020a). According to Alsharif et al. (2021d); Jordao et al. (2017) the fMRI and EEG are the most brain imaging tools that applied to record the brain activity signal of the consumers toward marketing stimuli such ad advertising campaigns. Meanwhile, according to dos Santos et al. (2015), the ET is the most common physiological tool. Lim (2018) indicates that brain-imaging tools such as $\mathrm{FMRI}$ and EEG are the most popular among scholars, followed by physiological tools such as ET.

Overall, we suggest excluding some techniques such as PET and TMS in neuromarketing research. Whether an invasive tool, use an injection of some chemical materials (e.g., fluorodeoxyglucose) in the blood vessels or harmful to use in consumer research. MEG needs a specific environment such as low temperature (estimated zero), too expensive, and limited to recording the cortical regions, making it inappropriate for marketing research. The EEG technique can substitute the SST technique because EEG has more accuracy and reliability, which leads us to infer that EEG and fMRI are convenient tools (Alsharif et al., 2021d; Fortunato et al., 2014; Koc \& Boz, 2018). fNIRS is a noninvasive tool, which uses the hemodynamic responses associated with neuronal activities (Krampe et al., 2018). It is employed to record modifications in haemoglobin flow (e.g., oxyhaemoglobin and deoxyhaemoglobin) during brain activity and establish a map of the blood oxygenation in the local brain area (active regions in the brain required more oxyhaemoglobin) (Ernst et al., 2013; Jackson \& Kennedy, 2013). According to the literature, it has acceptable temporal accuracy (estimated in seconds) (Alvino et al., 2020) and low spatial accuracy (estimated in $4 \mathrm{~cm}$ ) (Krampe et al., 2018), which has only the ability to measure the cerebral regions (Cakir et al., 2018), which lead to infer that this tool is not suitable to measure the deep structure of the brain. Several studies have been used fNIRS technique to study the purchase behaviour and brand (Cakir et al., 2018; Krampe et al., 2018). Therefore, we selected three tools for this review: $\mathrm{FMRI}, E E G$, and $E T$, employed to record the brain and somatic activity signals of the consumers toward marketing stimuli such as advertisements and brands. Table 1 shows the pros and cons for each common tools, what does it measure and when does it use?

\subsection{Functional magnetic resonance imaging}

fMRI is a metabolism and non-invasive technique. fMRI is used to measure the level of oxygen in the blood vessels wherein the activity regions in the brain need more oxygenated blood than inactive regions; thereby, the activity regions in the brain will produce stronger signals than others (Morin, 2011; Murray \& Antonakis, 2019). The participant have to lay into the fMRI tube, wherein the participant's head is surrounded by a huge magnet to measure the activity regions in the brain. In addition, the participant should not move throughout the experiment because the magnetic is too sensitive toward any movement of participants (Alsharif et al., 2020b; Pradeep, 2010). Marketing stimuli (e.g., picture, videos, product, logo, brand) will be displayed on the participants, the activity regions in the brain will need more oxygenated blood than inactive regions. The blood vessels in the activity regions will dilate to receive a great amount of oxygenated blood and glucose which active regions need it. As a result of that the activity regions produce a stronger magnetic field than the inactive ones, which is leading to changes in the magnetic field (Gani et al., 2015; Zurawicki, 2010). Therefore, $\mathrm{fMRI}$ records the signals of the active regions and displays the activity regions of the brain in threedimensions view on the computer screen, which appears in grey colour named blood oxygen leveldependent (Boksem \& Smidts, 2015; Cabre et al., 2019). fMRI tool enables the record of 1-10 mm3 in the deep structure of the brain because it has an excellent spatial resolution. Meanwhile, it has acceptable temporal accuracy, estimated 1-6 seconds (s) to start recording the activity regions in the brain. Therefore, fMRI is deemed as one of the best techniques in marketing research to measure the neural responses of consumers such as emotion (e.g., valence, appeal, engagement, and arousal) toward brands (e.g., recall, recognition, preference, and liking) and advertising campaign (e.g., effectiveness) (Alsharif et al., 2021d; Casado-Aranda et al., 2018; Chen \& Morris, 2016; Venkatraman et al., 2015). 
Table 1: The most common popular tools applied in marketing research.

\begin{tabular}{|c|c|c|c|c|c|}
\hline Tool & Reference & $\begin{array}{c}\text { What does it } \\
\text { measure? }\end{array}$ & When does it use? & Pros & Cons \\
\hline fMRI & 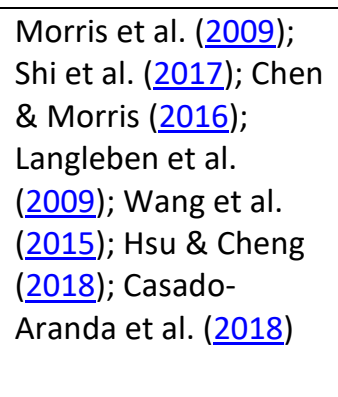 & $\begin{array}{l}\text { Memory, } \\
\text { dimension of } \\
\text { emotion (i.e., } \\
\text { valence and } \\
\text { arousal) } \\
\text { perception, } \\
\text { attention, } \\
\text { engagement, } \\
\text { reward. }\end{array}$ & $\begin{array}{l}\text { Testing new } \\
\text { products, ads, } \\
\text { brands, design of the } \\
\text { package, prices, } \\
\text { reposition and } \\
\text { quality of a product, } \\
\text { predicting } \\
\text { consumers' purchase } \\
\text { decisions. }\end{array}$ & $\begin{array}{l}\text { High spatial resolution, } \\
\text { trustable for } \\
\text { measuring the neural } \\
\text { correlates of cognitive } \\
\text { and emotional } \\
\text { processes. }\end{array}$ & $\begin{array}{l}\text { Low temporal } \\
\text { resolution, } \\
\text { expensive, non- } \\
\text { portable, } \\
\text { uncomfortable, data } \\
\text { analysis is quite } \\
\text { complex, need a } \\
\text { wide place. }\end{array}$ \\
\hline EEG & $\begin{array}{l}\text { Wang et al. (2016); } \\
\text { Cartocci et al. (2017); } \\
\text { Wei et al. (2018); } \\
\text { Harris et al. (2019); } \\
\text { García-Madariaga et } \\
\text { al. (2020); Eijlers et al. } \\
(\underline{2020})\end{array}$ & $\begin{array}{l}\text { Cognitive and } \\
\text { emotional } \\
\text { processes, } \\
\text { engagement, } \\
\text { and } \\
\text { excitement. }\end{array}$ & $\begin{array}{l}\text { Testing ads (e.g., } \\
\text { print, images, online, } \\
\text { videos), products } \\
\text { (e.g., label, brand, } \\
\text { price, design), } \\
\text { websites (e.g., } \\
\text { design, brightness, } \\
\text { usability). }\end{array}$ & $\begin{array}{l}\text { High temporal } \\
\text { resolution, quite } \\
\text { inexpensive, } \\
\text { Wearable, non- } \\
\text { invasive, data analysis } \\
\text { is quite } \\
\text { straightforward, } \\
\text { trustable for } \\
\text { measuring cognitive } \\
\text { information } \\
\text { processing, enables } \\
\text { comparisons between } \\
\text { cortical hemispheres } \\
\text { (e.g., left and right). }\end{array}$ & $\begin{array}{l}\text { Low spatial } \\
\text { resolution, findings } \\
\text { prone to influence } \\
\text { through artefacts, } \\
\text { unable to record } \\
\text { emotional arousal. }\end{array}$ \\
\hline ET & 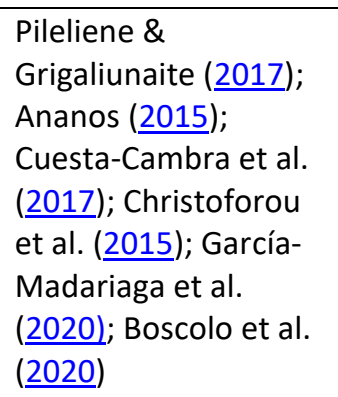 & $\begin{array}{l}\text { Attention, } \\
\text { visual stimuli, } \\
\text { fixation, pupil } \\
\text { dilation, eye } \\
\text { movements, } \\
\text { saccade, } \\
\text { excitement. }\end{array}$ & $\begin{array}{l}\text { Testing ads (e.g., } \\
\text { picture, videos, } \\
\text { colour, brightness), } \\
\text { product (e.g., brand, } \\
\text { label, position in- } \\
\text { store), design (e.g., } \\
\text { product, website, } \\
\text { package, the usability } \\
\text { of the website). }\end{array}$ & $\begin{array}{l}\text { Portable, low cost, and } \\
\text { non-invasive tool }\end{array}$ & $\begin{array}{l}\text { Not work very well } \\
\text { with glasses, } \\
\text { eyelashes, and } \\
\text { lenses }\end{array}$ \\
\hline
\end{tabular}

Source: Adopted by Alsharif et al. (2021d)

FMRI is used to know how different marketing stimuli impact buying decisions, including exposure to a certain advertisement (Morin, 2011; Smidts et al., 2014). For high-quality information, $\mathrm{FMRI}$ and PET techniques can be combined because the PET technique can record what is happening in the brain moment-by-moment, while $\mathrm{fMRI}$ is more appropriate to identify the activity regions in the brain accurately. But using the PET technique in marketing research is limited due to the PET technique uses chemical material which is injecting into the blood-vessel to record the activity regions in the brain, which is not convenient for participants (Fortunato et al., 2014; Sebastian, 2014). However, these tools are huge and require big places; thereby, it is impossible to use them in realistic circumstances, and last but not least, costly (Cherubino et al., 2019). A number of studies have used fMRI to measure the neural responses of consumers behaviour toward marketing stimuli (Al-Kwifi, 2016; Fehse et al., 2017). For example, Fehse et al. (2017) conducted an experiment to investigate the neural correlates of the perceptions toward two types of brands (organic and popular brands). The findings illustrated that a stronger activity in the medial prefrontal cortex (mPFC) for popular brands, while a stronger activity in the dorsolateral prefrontal cortex (dIPFC), wherein the lateral and medial PFC have vital role in influencing decisionmaking. Chen and Morris (2016) investigated the 
activity regions in the brain that are relevant to the emotional dimensions (e.g., arousal, pleasure) evoked by TV ads. Their findings revealed that the pleasure and displeasure dimensions are correlated with more activity in the gyri regions (e.g., inferior frontal and middle temporal gyri), while the low and high arousal is associated with gyrus regions (e.g., the right superior temporal and right middle frontal gyrus).

\subsection{Electroencephalography}

EEG is the most technology used in marketing practices before the release of the $\mathrm{fMRI}$ technique because of its less expensive and excellent temporal resolution (Alsharif et al., 2021d; Cruz et al., 2016; Lee et al., 2017; Telpaz et al., 2015). EEG is a non-invasive electrical technique, which is using electrodes placed on the consumer's scalp to measure the voltage changes of frequencies at scalp toward marketing stimuli in milliseconds (Cherubino et al., 2019; Davis, 2019; Eijlers et al., 2020; Kumar, 2015). According to the literature, EEG has five frequency bands such as delta (less than 4 hertz $(\mathrm{Hz}))$, theta $(4-7 \mathrm{~Hz})$, alpha $(8-15 \mathrm{~Hz})$, beta (16-31 $\mathrm{Hz}$ ), and gamma (larger than $32 \mathrm{~Hz}$ ) (Wei et al., 2018). EEG has an excellent temporal resolution (estimated in milliseconds) (Ohme et al., 2011; Telpaz et al., 2015), but it has a poor spatial resolution because it enables only to record the cortical activity regions of the brain (estimated in $1 \mathrm{~cm}$ ) (Telpaz et al., 2015; Zurawicki, 2010). In addition, EEG uses a 10-20 system, which is a globally recognised method. This system is used to express the locations of electrodes on the scalp of the participants such as prefrontal (Fp), frontal (F), occipital $(\mathrm{O})$, parietal $(P)$, temporal $(T)$, and central $(C)$. EEG uses an equal number of electrodes on the right and left parts of the head (Rawnaque et al., 2020; Silverman, 1965). It also uses to understand how a consumer is reacting to an advertisement or to understand what is happening in a consumer's brain when interacting with a salesperson (Telpaz et al., 2015). Increasing the number of electrodes enables the record of the extremely low frequency of the active signals (Calvert \& Thesen, 2004; Du Plessis, 2011; Pradeep, 2010; Samsuri et al., 2016b).

A number of studies have used EEG/ event-related potential (ERP) to measure the consumers' behaviour toward marketing stimuli such as ads, products (Ciorciari et al., 2019; Eijlers et al., 2020; Samsuri et al., 2016a; Samsuri et al., 2016b). For example, the ERP and ET investigation to measure the attention level, pupil dilation, and fixation toward the display design of car advertisements. The findings revealed that the higher amplitudes of the ERP component (N100 refers to perception and P300 refers to attention and memory) were found during the right lateral grouped view of cars. Therefore, the right lateral grouped view of the car has higher interest than the left lateral grouped view of the car. Heat maps showed that the red colour of the car has a common interest in both views of car (Samsuri et al., 2016b). Similarly, Samsuri et al. (2016a) found that the higher amplitudes and shorter latencies of the ERP component were found during the left lateral singular view, therefore, the left lateral singular has higher visual attention and perception than the right lateral singular view of cars. In addition, heat maps showed that the black car's left lateral singular view has a higher interest, while the red car view has a higher interest in the right lateral singular. Consequently, both experiments can help automotive firms better understand visual attention, thoughts, and perceptions of consumers toward automotive display, improving marketing strategies such as promotion. In other EEG studies, Eijlers et al. (2020) investigated the arousal evoked in response to advertisements. The findings showed that arousal is positively connected to prominent ads in the population and negatively to consumer attitude toward these ads. Harris et al. (2019) examined the effectiveness of emotion-based ads on the public health sector. The findings revealed that emotion-based ads are more effective in decision-making than rationalbased ads.

\subsection{Eye-Tracking}

Eye-tracking (ET) is employed to record eye movement or saccades (fast eye movement), fixation (look at a specific point), and pupil dilation (pupil size). It allows measuring the various processes of the individual's brain toward stimuli such as emotional responses (Guo et al., 2018; Wang et al., 2010). Accordingly, it is an effective tool for experimental psychology and neurological research because of the relationship between visual attention and eye movements (Hoffman, 1998). ET is a convenient tool to record where eyes are looking at and what eyes are looking for, for example, it records the fixation time (i.e., spent time that the consumer keeps his/her eyes on a specific thing), saccade (i.e., time that the consumer's eyes jump from one to another fixation point); therefore, collect information about interest area (Alsharif et al., 2020b; Cherubino et al., 2019). The eye fixation time during reading text was estimated at 200 milliseconds (ms). Meanwhile, watching the video scene was estimated at $350 \mathrm{~ms}$. Saccade eye is estimated at $200 \mathrm{~ms}$ (Rayner, 2009). According to literature, fixation and saccades are called scan and analyse visual stimuli, interest area (Fortunato et al., 2014). 
ET has been widely employed in neuromarketing research to investigate visual and engagement behaviour (Zamani et al., 2016), many scholars use ET in both environments (i.e., lab and the factual world) (King et al., 2019). In marketing research, the ET technique has been largely used to evaluate the visual behaviour of consumers toward marketing stimuli, for example, but not limited to the design of packaging and products. Many scholars and practitioners have used the ET and EEG techniques together to collect more accurate information about consumers' emotional and cognitive reactions toward stimuli (Alsharif et al., 2021c; Guixeres et al., 2017). For example, it has investigated the influence of color temperature of ad and the gender of spokesperson on the advertising effectiveness. Their findings suggested that the warm color temperature attracts more visual attention to the advertisement, generating a positive implicit attitude to the advertisement and inducing the buying intentions of the advertised products compared with cool color temperature advertisements whether the spokesperson's female or male celebrity (Pileliene \& Grigaliunaite, 2017). Therefore, the color temperature impacts the effectiveness of the advertising spokesperson and advertising effectiveness.

\subsection{CONCLUSION AND FUTURE DIRECTIONS}

Marketing research still largely relies on traditional methods to study consumers' behaviour wherein consumers consciously report on their experiences and thoughts. While unconscious behaviour is largely unmeasured by conventional methods. Therefore, the NM give marketers, researchers, and practitioners an unrivalled opportunity to better understand unconscious consumers' behaviour and pre-purchase and post-purchase behaviour toward marketing stimuli (e.g., brands, products) by using neuroimaging and physiological tools such as $\mathrm{AMRI}, \mathrm{EEG}$, and ET. This is expected to increase the effectiveness of marketing stimuli, such as product and brand preference (likes/dislikes), the perceived value of product, and brand and promotion. For example, fMRI is a noninvasive and metabolic technique to measure the activity regions of the consumer's brain by measuring the oxygenated and deoxygenated blood, wherein the active regions of the brain need more oxygenated blood than inactive regions. EEG is a non-invasive and electrical technique to measure the changes in voltage at the scalp regions, wherein use electrodes at the scalp within 10-20 standard system. ET is a physiological tool to measure eye movements, fixation, saccade, pupil dilation toward visual stimuli. These techniques can identify the weaknesses and address them, meanwhile, identify strengths and enhance them.

Although NM faces many ethical issues (e.g., autonomy, privacy) and challenges (e.g., cost, need experts, lack to access to resources), it is a novel method to analyse the consumer's behaviour. It provides valuable information for marketing research. For example, it gives proactive steps to marketers, researchers, and practitioners to better understand consumer behaviour and decisionmaking processes toward various stimuli such as brands. This paper is providing an overview of NM domain and techniques such as the fMRI, EEG, and ET. To end, scholars have to use NM for the sake of improving people's lives, not for their own goals.

\begin{abstract}
Acknowledgements: The authors would like to thank Universiti Teknologi Malaysia (UTM), Azman Hashim International Business School (AHIBS) for supporting this study.
\end{abstract}

Author Contributions: AHA: Conceptualisation and writing the original draft. NZMS and RB: Supervision, review and editing. All authors have read and agreed to the published version of the manuscript.

Conflicts of Interest: The authors declare no conflict of interest.

\section{References}

Al-Kwifi, S. O. (2016). The role of $\mathrm{FMRI}$ in detecting attitude toward brand switching: an exploratory study using high technology products. Journal of Product \& Brand Management, 25(2), 208-218. https://doi.org/10.1108/jpbm-12-2014$\underline{0774}$

Alsharif, A. H., Salleh, N. Z. M., \& Baharun, R. (2020a). Research trends of neuromarketing: A bibliometric analysis. Journal of Theoretical and Applied Information Technology, 98(15), 2948-2962.

Alsharif, A. H., Salleh, N. Z. M., \& Baharun, R. (2021a). The neural correlates of emotion in decision-making. International Journal of Academic Research in Business and Social Sciences, 11(7), 64-77. https://doi.org/10.6007/ijarbss/v11-i7/10075

Alsharif, A. H., Salleh, N. Z. M., \& Baharun, R. (2021b). To better understand the role of emotional processes in decisionmaking. International Journal of Academic Research in Economics and Management Sciences, 10(2), 49-67. https://doi.org/10.6007/ijarems/v10-i2/9883 
Alsharif, A. H., Salleh, N. Z. M., Baharun, R., \& Effandi, Y. M. (2021c). Consumer behaviour through neuromarketing approach. Journal of Contemporary Issues in Business and Government, 27(3), 344-354. https://doi.org/10.47750/cibg.2021.27.03.048

Alsharif, A. H., Salleh, N. Z. M., Baharun, R., Rami Hashem E., A., Mansor, A. A., Ali, J., \& Abbas, A. F. (2021d). Neuroimaging techniques in advertising research: Main applications, development, and brain regions and processes. Sustainability, 13(11), 6488-6513. https://doi.org/10.3390/su13116488

Alsharif, A. H., Salleh, N. Z. M., Baharun, R., \& Safaei, M. (2020b). Neuromarketing approach: An overview and future research directions. Journal of Theoretical and Applied Information Technology, 98(7), 991-1001.

Alvino, L., Pavone, L., Abhishta, A., \& Robben, H. (2020). Picking your brains: Where and how neuroscience tools can enhance marketing research. Frontiers in Neuroscience, 14(2), 1-25. https://doi.org/10.3389/fnins.2020.577666

Ananos, E. (2015). Eye tracker technology in elderly people: How integrated television content is paid attention to and processed. Comunicar, 23(45), 75-83. https://doi.org/10.3916/c45-2015-08

Boksem, M. A. S., \& Smidts, A. (2015). Brain responses to movie trailers predict individual preferences for movies and their population-wide commercial success. Journal of Marketing Research, 52(4), 482-492. https://doi.org/10.1509/jmr.13.0572

Boscolo, J. C., Oliveira, J. H. C., Maheshwari, V., \& Giraldi, J. D. E. (2020). Gender differences: Visual attention and attitude toward advertisements. Marketing Intelligence \& Planning, 39(2), 300-314. https://doi.org/10.1108/mip-11-2019-0598

Cabre, J. J., Mur, T., Costa, B., Barrio, F., Lopez-Moya, C., Sagarra, R., . . Catalan Diabet Prevention Res, G. (2019). Feasibility and effectiveness of electrochemical dermal conductance measurement for the screening of diabetic neuropathy in primary care. decoding study. Journal of Clinical Medicine, 8(5), 13. https://doi.org/10.3390/jcm8050598

Cakir, M. P., Çakar, T., Girisken, Y., \& Yurdakul, D. (2018). An investigation of the neural correlates of purchase behavior through fNIRS. European Journal of Marketing. https://doi.org/10.1108/ejm-12-2016-0864

Calvert, G. A., \& Thesen, T. (2004). Multisensory integration: Methodological approaches and emerging principles in the human brain. Journal of Physiology-Paris, 98(1-3), 191-205. https://doi.org/10.1016/i.jphysparis.2004.03.018

Cartocci, G., Caratù, M., Modica, E., Maglione, A. G., Rossi, D., Cherubino, P., \& Babiloni, F. (2017). Electroencephalographic, heart rate, and galvanic skin response assessment for an advertising perception study: Application to antismoking public service announcements. Journal of Visualized Experiments, 3(126), 55872-55881. https://doi.org/10.3791/55872

Cartocci, G., Modica, E., Rossi, D., Cherubino, P., Maglione, A. G., Colosimo, A., . . Babiloni, F. (2018). Neurophysiological measures of the perception of antismoking public service announcements among young population. Frontiers in Human Neuroscience, 12(2), 231-248. https://doi.org/10.3389/fnhum.2018.00231

Casado-Aranda, L. A., Van der Laan, L. N., \& Sánchez-Fernández, J. (2018). Neural correlates of gender congruence in audiovisual commercials for gender-targeted products: An fMRI study. Human Brain Mapping, 39(11), 4360-4372. https://doi.org/10.1002/hbm.24276

Chen, F., \& Morris, J. D. (2016). Decoding neural responses to emotion in television commercials. Journal of Advertising Research, 56(2), 11-28. https://doi.org/10.2501/jar-2016-016

Cherubino, P., Caratù, M., Modica, E., Rossi, D., Trettel, A., Maglione, A. G., . . Babiloni, F. (2017). Assessing cerebral and emotional activity during the purchase of fruit and vegetable products in the supermarkets. In Neuroeconomic and Behavioral Aspects of Decision Making (pp. 293-307). Springer. https://doi.org/10.1007/978-3-319-62938-4 19

Cherubino, P., Martinez-Levy, A. C., Caratu, M., Cartocci, G., Di Flumeri, G., Modica, E., . . Trettel, A. (2019). Consumer behaviour through the eyes of neurophysiological measures: State of the art and future trends. Computational Intelligence and Neuroscience, 3(2), 01-41. https://doi.org/10.1155/2019/1976847

Christoforou, C., Christou-Champi, S., Constantinidou, F., \& Theodorou, M. (2015). From the eyes and the heart: A novel eyegaze metric that predicts video preferences of a large auidence. Frontiers in Psychology, 6(2), 579-590. https://doi.org/10.3389/fpsyg.2015.00579

Ciorciari, J., Pfeifer, J., \& Gountas, J. (2019). An EEG study on emotional intelligence and advertising message effectiveness. Behavioral Sciences, 9(8), 15. https://doi.org/10.3390/bs9080088

Colaferro, C. A., \& Crescitelli, E. (2014). The contribution of neuromarketing to the study of consumer behavior. Brazilian Business Review, 11(3), 130-153. http://dx.doi.org/10.15728/bbr.2014.11.3.6

Cruz, C., Medeiros, J., Hermes, L., Marcon, A., \& Marcon, E. (2016). Neuromarketing and the advances in the consumer behaviour studies: A systematic review of the literature. International Journal of Business Globalisation, 17(3), 330-351. https://doi.org/10.1504/ijbg.2016.078842

Cuesta-Cambra, U., Niño-González, J.-I., \& Rodríguez-Terceño, J. (2017). The cognitive processing of an educational app with EEG and eye tracking. Comunicar. Media Education Research Journal, 25(52), 41-50. https://doi.org/10.3916/c52-201704

Davis, J. J. (2019). Advertising Research: Theory and practice (2nd ed.). New York, USA. Pearson Higher Education.

dos Santos, R. d. O. J., de Oliveira, J. H. C., Giraldi, J. d. M. E., \& Tech, A. R. B. (2015). Public policies and selective visual attention: The effectiveness of awareness messages among young people about the consumption of alcoholic beverages in Brazil. Brazilian Journal of Science and Technology, 2(1), 1-9. https://doi.org/10.1186/s40552-015-0010-3 
Du Plessis, E. (2011). The branded mind: What neuroscience really tells us about the puzzle of the brain and the brand. Philadelphia, USA. Kogan Page Publishers.

Eijlers, E., Boksem, M. A. S., \& Smidts, A. (2020). Measuring neural arousal for advertisements and its relationship with advertising success. Frontiers in Neuroscience, 14(4), 736-748. https://doi.org/10.3389/fnins.2020.00736

Ernst, L. H., Plichta, M. M., Lutz, E., Zesewitz, A. K., Tupak, S. V., Dresler, T., . . Fallgatter, A. J. (2013). Prefrontal activation patterns of automatic and regulated approach-avoidance reactions-A functional near-infrared spectroscopy (fNIRS) study. Cortex, 49(1), 131-142. https://doi.org/10.1016/i.cortex.2011.09.013

Eser, Z., Isin, F. B., \& Tolon, M. (2011). Perceptions of marketing academics, neurologists, and marketing professionals about neuromarketing. Journal of Marketing Management, 27(7), 854-868. https://doi.org/10.1080/02672571003719070

Fehse, K., Simmank, F., Gutyrchik, E., \& Sztrokay-Gaul, A. (2017). Organic or popular brands-food perception engages distinct functional pathways: An fMRI study. Cogent Psychology, 4, 11. https://doi.org/10.1080/23311908.2017.1284392

Fortunato, V. C. R., Giraldi, J. D. M. E., \& Oliveira, J. H. C. D. (2014). A review of studies on neuromarketing: Practical results, techniques, contributions and limitations. Journal of Management Research, 6(2), 201-221. https://doi.org/10.5296/jmr.v6i2.5446

Fugate, D. L. (2007). Neuromarketing: A layman's look at neuroscience and its potential application to marketing practice. Journal of Consumer Marketing, 24(7), 385-394. https://doi.org/10.1108/07363760710834807

Gani, M., Reza, S., \& Rabi, M. (2015). Neuromarketing: Methodologies of marketing science. Paper presented at the Proceedings of The 3rd International Conference On Economics, Management, Law and Education (EMLE). https://doi.org/10.15224/978-1-63248-071-2-38

García-Madariaga, J., Moya, I., Recuero, N., \& Blasco, M.-F. (2020). Revealing unconscious consumer reactions to advertisements that include visual metaphors. a neurophysiological experiment. Frontiers in Psychology, 11(3), 760-776. https://doi.org/10.3389/fpsyg.2020.00760

Guixeres, J., Bigné, E., Ausín Azofra, J. M., Alcañiz Raya, M., Colomer Granero, A., Fuentes Hurtado, F., \& Naranjo Ornedo, V. (2017). Consumer neuroscience-based metrics predict recall, liking and viewing rates in online advertising. Frontiers in Psychology, 8(3), 1808. https://doi.org/10.3389/fpsyg.2017.01808

Guo, F., Ye, G., Duffy, V. G., Li, M., \& Ding, Y. (2018). Applying eye tracking and electroencephalography to evaluate the effects of placement disclosures on brand responses. Journal of Consumer Behaviour, 17(6), 519-531. https://doi.org/10.1002/cb.1736

Harris, J. M., Ciorciari, J., \& Gountas, J. (2019). Consumer neuroscience and digital/social media health/social cause advertisement effectiveness. Behavioral Sciences, 9(4), 25. https://doi.org/10.3390/bs9040042

Hoffman, J. (1998). Visual attention and eye movements. Attention, 31(2), 119-153.

Hsu, M. Y. T., \& Cheng, J. M.-S. (2018). fMRI neuromarketing and consumer learning theory: Word-of-mouth effectiveness after product harm crisis. European Journal of Marketing, 52(1/2), 199-223. https://doi.org/10.1108/ejm-12-2016-0866

Jackson, P. A., \& Kennedy, D. O. (2013). The application of near infrared spectroscopy in nutritional intervention studies. Frontiers in Human Neuroscience, 7(2), 473-479. https://doi.org/10.3389/fnhum.2013.00473

Jordao, I. L. D. S., Souza, M. T. D., Oliveira, J. H. C. D., \& Giraldi, J. D. M. E. (2017). Neuromarketing applied to consumer behaviour: an integrative literature review between 2010 and 2015. International Journal of Business Forecasting and Marketing Intelligence, 3(3), 270-288. https://doi.org/10.1504/ijbfmi.2017.10006047

King, A., Bol, N., Cummins, R., \& John, K. (2019). Improving visual behavior research in communication science: An overview, review, and reporting recommendations for using eye-tracking methods. Communication Methods and Measures, 13(3), 149-177. https://doi.org/10.1080/19312458.2018.1558194

Koc, E., \& Boz, H. (2018). How can consumer science be used for gaining information about consumers and the market?: The role of psychophysiological and neuromarketing research. In Consumer Science and Strategic Marketing (pp. 129-152). Netherlands. Elsevier. https://doi.org/10.1016/b978-0-08-101007-5.00013-0

Krampe, C., Gier, N. R., \& Kenning, P. (2018). The Application of Mobile fNIRS in Marketing Research - Detecting the "FirstChoice-Brand" Effect. Frontiers in Human Neuroscience, 12(4), 433-444. https://doi.org/10.3389/fnhum.2018.00433

Kühn, S., Strelow, E., \& Gallinat, J. (2016). Multiple "buy buttons" in the brain: Forecasting chocolate sales at point-of-sale based on functional brain activation using fMRI. Neuroimage, 136, 122-128. https://doi.org/10.1016/j.neuroimage.2016.05.021

Kumar, S. (2015). Neuromarketing: The new science of advertising. Universal Journal of Management, 3(12), $524-531$. https://doi.org/10.13189/ujm.2015.031208

Langleben, D. D., Loughead, J. W., Ruparel, K., Hakun, J. G., Busch-Winokur, S., Holloway, M. B., ... Lerman, C. (2009). Reduced prefrontal and temporal processing and recall of high "sensation value" ads. Neuroimage, 46(1), $219-225$. https://doi.org/10.1016/i.neuroimage.2008.12.062

Lee, N., Brandes, L., Chamberlain, L., \& Senior, C. (2017). This is your brain on neuromarketing: reflections on a decade of research. Journal of Marketing Management, 33(11-12), 878-892.

Lim, W. M. (2018). Demystifying neuromarketing. Journal of Business Research, 91, 205-220. https://doi.org/10.1016/i.jbusres.2018.05.036 
Lindstrom, M. (2009). Buyology: How everything we believe about why we buy is wrong (1st ed.). London, UK. Random House.

Mansor, A. A., \& Isa, S. M. (2020). Fundamentals of neuromarketing: What is it all about? Neuroscience Research Notes, 3(4), 22-28. https://doi.org/10.31117/neuroscirn.v3i4.58

Morin, C. (2011). Neuromarketing: The new science of consumer behavior. Society, 48(2), 131-135. https://doi.org/10.1007/s12115-010-9408-1

Morris, J. D., Klahr, N. J., Shen, F., Villegas, J., Wright, P., He, G. J., \& Li, Y. J. (2009). Mapping a Multidimensional Emotion in Response to Television Commercials. Human Brain Mapping, 30(3), 789-796. https://doi.org/10.1002/hbm.20544

Murray, M. M., \& Antonakis, J. (2019). An introductory guide to organizational neuroscience. 22(2), 6-16. https://doi.org/10.1177/1094428118802621

Ohme, R., Matukin, M., \& Pacula-Lesniak, B. (2011). Biometric measures for interactive advertising research. Journal of interactive advertising, 11(2), 60-72. https://doi.org/10.1080/15252019.2011.10722185

Orzan, G., Zara, I., \& Purcarea, V. (2012). Neuromarketing techniques in pharmaceutical drugs advertising. A discussion and agenda for future research. Journal of medicine and life, 5(4), 428-432.

Pileliene, L., \& Grigaliunaite, V. (2017). Relationship between spokesperson's gender and advertising color temperature in a framework of advertising effectiveness. Scientific Annals of Economics and Business, 64(2), 1-13. https://doi.org/10.1515/saeb-2017-0036

Pradeep, A. K. (2010). The buying brain: Secrets for selling to the subconscious mind. New York, USA. John Wiley \& Sons Inc.

Ramsoy, T. Z. (2015). Introduction to neuromarketing \& consumer neuroscience. Rørvig, Denmark. Neurons Inc.

Rawnaque, F., Rahman, M., Anwar, S. M., Vaidyanathan, R., Chau, T., Sarker, F., \& Al Mamun, A. (2020). Technological advancements and opportunities in Neuromarketing: A systematic review. Brain Informatics, 7(1), 1-19. https://doi.org/10.1186/s40708-020-00109-x

Rayner, K. (2009). Eye movements and attention in reading, scene perception, and visual search. Quarterly Journal of Experimental Psychology, 62(8), 1457-1506. https://doi.org/10.4324/9780203809617

Rossi, D., Modica, E., Maglione, A. G., Venuti, I., Brizi, A., Babiloni, F., \& Cartocci, G. (2017). Visual evaluation of health warning cues in anti smoking PSAs images. Paper presented at the IEEE 3rd International Forum on Research and Technologies for Society and Industry (RTSI). https://doi.org/10.1109/rtsi.2017.8065948

Samsuri, N., Begum, T., Reza, F., Omar, H., Yusoff, N., Idris, B., \& Isa, S. M. (2016a). Left Lateral Singular (LLS) view enhances attention at stimulus discrimination during Automobile display setting revealed by EEG/ERP and Eye Tracking Technique. International Journal of Enhanced Research in Science, Technology \& Engineering, 5(5), 1-9.

Samsuri, N., Reza, F., Begum, T., Yusoff, N., Idris, B., Omar, H., \& Isa, S. M. (2016b). Electrophysiological quantification of underlying mechanism of decision making from auto dealers advertisement-a neuromarketing research. Paper presented at the AIP Conference Proceedings. https://doi.org/10.1063/1.4966084

Sebastian, V. (2014). Neuromarketing and evaluation of cognitive and emotional responses of consumers to marketing stimuli. Procedia Social Behavioral Sciences, 127(2), 753-757. https://doi.org/10.1016/j.sbspro.2014.03.349

Shi, Z. H., Wang, A. L., Aronowitz, C. A., Romer, D., \& Langleben, D. D. (2017). Individual differences in the processing of smoking-cessation video messages: An imaging genetics study. Biological psychology, 128, 125-131. https://doi.org/10.1016/i.biopsycho.2017.07.019

Silverman, D. (1965). The anterior temporal electrode and the ten-twenty system. American Journal of EEG Technology, 5(1), 11-14. https://doi.org/10.1080/00029238.1965.11080641

Smidts, A., Hsu, M., Sanfey, A. G., Boksem, M. A., Ebstein, R. B., Huettel, S. A., . . Knutson, B. (2014). Advancing consumer neuroscience. Marketing Letters, 25(3), 257-267. https://doi.org/10.1007/s11002-014-9306-1

Stanton, S., Armstrong, W., \& Huettel, S. (2017). Neuromarketing: Ethical implications of its use and potential misuse. Journal of Business Ethics, 144(4), 799-811. https://doi.org/10.1007/s10551-016-3059-0

Telpaz, A., Webb, R., \& Levy, D. J. (2015). Using EEG to predict consumers' future choices. Journal of Marketing Research, 52(4), 511-529. https://doi.org/10.1509/imr.13.0564

Venkatraman, V., Dimoka, A., Pavlou, P. A., Vo, K., Hampton, W., Bollinger, B., ... Winer, R. S. (2015). Predicting advertising success beyond traditional measures: New insights from neurophysiological methods and market response modeling. Journal of Marketing Research, 52(4), 436-452. https://doi.org/10.2139/ssrn.2498095

Wang, J., Spezio, M., \& Camerer, C. F. (2010). Pinocchio's pupil: Using eyetracking and pupil dilation to understand truth telling and deception in sender-receiver games. American economic review, 100(3), 984-1007. https://doi.org/10.1257/aer.100.3.984

Wang, R. W., Chang, Y.-C., \& Chuang, S.-W. (2016). EEG spectral dynamics of video commercials: impact of the narrative on the branding product preference. Scientific Reports, 6(1), 36487-36498. https://doi.org/10.1038/srep36487

Wang, Y. Z., Chattaraman, V., Kim, H., \& Deshpande, G. (2015). Predicting purchase decisions based on spatio-temporal functional MRI features using machine learning. IEEE Transactions on Autonomous Mental Development, 7(3), $248-255$. https://doi.org/10.1109/tamd.2015.2434733 
Wei, Z., Wu, C., Wang, X., Supratak, A., Wang, P., \& Guo, Y. (2018). Using support vector machine on EEG for advertisement impact assessment. Frontiers in Neuroscience, 12, 76-88. https://doi.org/10.3389/fnins.2018.00076

Zamani, H., Abas, A., \& Amin, M. (2016). Eye tracking application on emotion analysis for marketing strategy. Journal of Telecommunication, Electronic and Computer Engineering (JTEC), 8(11), 87-91.

Zurawicki, L. (2010). Neuromarketing: Exploring the brain of the consumer. Boston, USA. Springer Science \& Business Media. https://doi.org/10.1007/978-3-540-77829-5 